Revista de Economia Política, vol. 28, no 2 (110), pp. 249-268, abril-junho/2008

\title{
O comportamento recente do investimento direto brasileiro no exterior em perspectiva
}

\author{
DANIELA CORRÊA \\ GILBERTO TADEU LIMA*
}

The recent behavior of the Brazilian direct investment abroad in perspective. This paper analyzes the recent behavior of the Brazilian direct investment abroad, as captured by an annual census conducted by the Central Bank of Brazil since 2001, by putting it in a broader perspective that includes international official data sources and early sample studies. Though the Central Bank has not been making available more disaggregated data than those analyzed here, it is intended to contribute to a better grasping of the perspectives of competitive internationalization of local firms, which is desirable not only as far as the external accounts are concerned, but also from the viewpoint of the technological capabilities of the local firms.

Keywords: internationalization; Brazilian investment abroad; competitiveness.

JEL Classification: L10; L20; F23.

Os investimentos no exterior, no contexto da globalização econômica, são vistos como um indicador adicional para entender a estratégia dos investidores internacionais. Até os anos 80, a inserção das empresas brasileiras no exterior era quase nula. Com a abertura econômica, porém, iniciou-se processo de internacionalização, que pode ser interpretado como uma tentativa de contornar a nova concorrência que entrava no país e um dos efeitos globalização, que é o crescente protecionismo dos países ricos.

O Banco Central do Brasil (BCB), a partir de 2001, passou a divulgar estatísticas referentes ao censo anual de capitais brasileiros no exterior. Segundo esses censos, a composição do capital brasileiro investido externamente (IDBE) é dada por uma parte majoritária que corresponde ao investimento direto (supe-

\footnotetext{
* Graduada em Economia na FEA-USP e mestranda em Economia pelo IE/UFRJ, e-mail: daniela_ gmc@yahoo.com.br; Professor do Departamento de Economia da FEA-USP, e-mail: giltadeu@usp.br. Submetido: Abril 2005; Aceito: Dezembro 2006.
} 
rior a $10 \%$ ), por empréstimos intercompanhias e investimento em carteira, entre outras modalidades de investimento.

As oscilações do fluxo de investimento brasileiro no exterior nos últimos anos foram significativas, como revela o Gráfico 1. De acordo com a UNCTAD (Conferência das Nações Unidas para o Comércio e Desenvolvimento), em 2000, esse fluxo atingiu cerca de US\$2,3 bilhões, e, no ano seguinte, caiu significativamente, finalizando o ano em US\$2,2 bilhões negativos. Já em 2002, o país foi a principal fonte de IDE da América Latina, registrando saída de US\$ 2,5 bilhões. No ano seguinte, os fluxos voltaram a cair consideravelmente, acompanhando a tendência de fracas performances na região. Em 2004, os investimentos no exterior alcançaram os US $\$ 9,8$ bilhões, o que firmou o país como um dos quatro principais investidores no exterior entre os emergentes e o principal da América Latina. Apenas duas grandes operações, porém, foram responsáveis por uma parcela considerável desse salto no volume de IDBE: a fusão entre a brasileira Ambev e a belga InterBrew e os empréstimos intercompanhia de firmas brasileiras para suas filiais no exterior. Em 2005, os investimentos apresentaram nova queda em relação ao ano anterior, não passando dos US\$ 2,5 bilhões.

Gráfico 1

Evolução IDBE

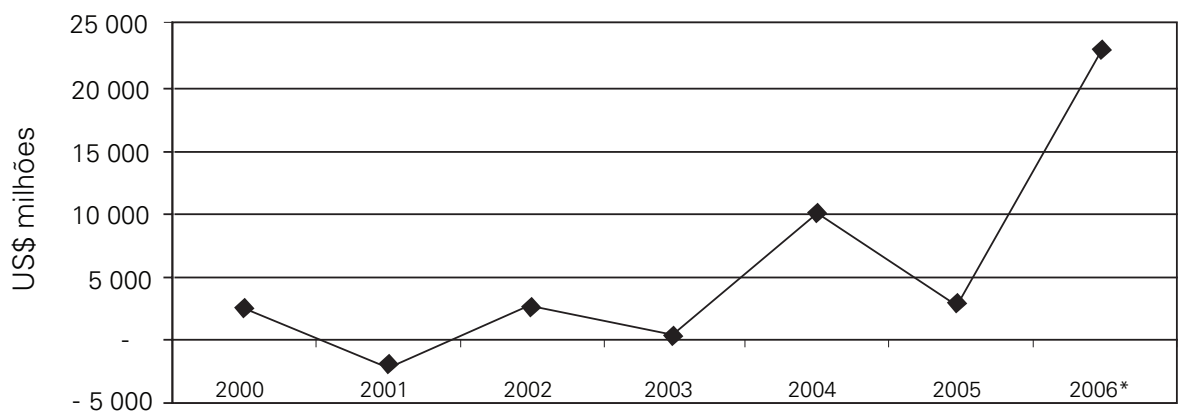

Atualmente, a grande expectativa é em relação aos números esperados para o ano de 2006, em que os investimentos diretos das empresas brasileiras no exterior devem superar, pela primeira vez, os investimentos estrangeiros no país. De acordo com os dados divulgados pelo BCB em outubro deste ano, os investimentos brasileiros no exterior acumulados no ano (até outubro) chegaram aos US\$22,8 bilhões, contra US\$13,6 bilhões de investimentos estrangeiros no país. Parte significativa do valor estimado, cerca de US\$13,2 bilhões, refere-se à compra da empresa canadense Inco pela Companhia Vale do Rio Doce. Porém, mesmo subtraído este montante, o resultado líquido é quase igual ao recorde nacional até então.

Conceitualmente, o investimento direto é dividido em participação societária e empréstimos intercompanhia. Em termos de estoque, de acordo com as de- 
clarações recebidas pelo BCB, o IDBE aumentou de US\$ 68,6 bilhões em 2001, para US\$111,7 bilhões em 2005. Destaca-se neste período o forte crescimento no estoque entre 2004 e 2005 , de cerca de $20 \%$, como sugerem os dados da Tabela 1 . O investimento direto superior a $10 \%$ respondeu em média por $80 \%$ do IDBE no período, ficando os demais $20 \%$ com os empréstimos intercompanhia. Apesar dos dados positivos, apenas uma pequena parcela do estoque do IDBE pode ser atribuída à produção internacional das multinacionais brasileiras, dado que mais de $70 \%$ desse volume está localizado em paraísos fiscais, e mais da metade em atividade de intermediação financeira. A grande participação de paraísos fiscais como destino de investimentos é muitas vezes conseqüência de uma estratégia de que as empresas se valem, que é efetuar seus investimentos no exterior através de holdings situadas nesses países.

Tabela 1

Estoques de Ativos

\begin{tabular}{|c|c|c|c|c|c|}
\hline & 2001 & 2002 & 2003 & 2004 & 2005 \\
\hline TOTAL & 68.598 & 72.325 & 82.692 & 93.243 & 111.741 \\
\hline Investimento Direto Brasileiro no Exterior & 49.689 & 54.423 & 54.892 & 69.196 & 79.259 \\
\hline investimento direto (superior a 10\%) & 42.584 & 43.397 & 44.769 & 54.027 & 65.418 \\
\hline empréstimos intercompanhia & 7.104 & 11.026 & 10.123 & 15.169 & 13.842 \\
\hline Investimento em Carteira & 5.163 & 4.449 & 5.946 & 8.224 & 9.586 \\
\hline portfólio - participação societária & 2.517 & 2.317 & 2.502 & 2.258 & 2.725 \\
\hline BDR & 483 & 71 & 94 & 94 & 84 \\
\hline portfólio - título da dívida - Longo Prazo (bônus / notas) & 577 & 941 & 1.491 & 2.899 & 3.602 \\
\hline portfólio - título da dívida - Curto Prazo (market instruments) & 1.585 & 1.120 & 1.859 & 2.973 & 3.176 \\
\hline Derivativos & 42 & 105 & 81 & 109 & 119 \\
\hline Financiamento & 155 & 313 & 186 & 68 & 98 \\
\hline Empréstimo & 696 & 537 & 687 & 631 & 726 \\
\hline Leasing / Arrend. Financeiro Longo Prazo & 1 & 3 & 0 & - & 1 \\
\hline Depósitos & 9.441 & 7.890 & 16.412 & 10.418 & 17.077 \\
\hline Outros Investimentos & 3.411 & 4.605 & 4.488 & 4.597 & 4.875 \\
\hline
\end{tabular}

Fonte: Banco Central do Brasil

Os elevados níveis de investimentos dirigidos a paraísos fiscais são uma tendência que se acentuou com o passar dos anos. A distribuição média do IDBE entre 1988 e 1992 mostra que países como Ilhas Cayman, Antilhas Holandesas, Bahamas e Bermudas respondiam por cerca de 39\% dos investimentos brasileiros no exterior. Já os dados mais recentes mostram que, entre os anos de $2001 \mathrm{e}$ 2005 , essa concentração esteve sempre acima de $70 \%$.

Excluindo-se os paraísos fiscais, são cinco os países que concentram os investimentos brasileiros no exterior: Argentina, Estados Unidos, Espanha, Portugal e Uruguai. ${ }^{1}$ A concentração de investimentos nesses países pode ser em parte explicada pela proximidade geográfica e pela atuação do Mercosul, para os ca-

\footnotetext{
${ }^{1}$ Nos anos de 2004 e, particularmente, a Holanda começou a se destacar como destino de IDBE, tendo atingido, neste último ano, posição de estoque superior a Argentina, Uruguai e Portugal.
} 
sos de Argentina e Uruguai, e também pela tradição comercial desenvolvida entre os países. As relações comerciais fornecem aos potenciais investidores um melhor conhecimento do mercado em que se pretende investir, reduzindo os riscos da operação.

Nesse contexto, este artigo propõe-se não apenas a desenvolver uma análise detalhada do comportamento recente do IDBE, tal como captado pelo censo de capitais brasileiros no exterior realizado pelo $\mathrm{BCB}$, mas, inclusive, a colocar esse comportamento em uma perspectiva mais ampla, com base em fontes oficiais internacionais e pesquisas amostrais realizadas no próprio país no passado relativamente recente. Muito embora o BCB não venha disponibilizando dados mais desagregados desses censos que os analisados neste artigo, pretende-se contribuir para o alargamento do horizonte de compreensão das perspectivas de internacionalização competitiva das empresas nacionais, algo desejável não somente em nível das contas externas (exportações líquidas, remessas de lucros e dividendos), mas, inclusive, da própria capacitação tecnológica das empresas nacionais (transferências e transbordamentos tecnológicos variados).

$\mathrm{O}$ que segue encontra-se assim estruturado. $\mathrm{O}$ item seguinte faz uma caracterização geral do IDBE e o compara com aquele de países em nível semelhante de desenvolvimento. O terceiro item resgata alguns elementos analítico-conceituais sobre a internacionalização produtiva de empresas e uma série de estudos amostrais anteriores acerca da internacionalização das empresas brasileiras, elementos e estudos à luz dos quais é então analisado, no item final, o comportamento do IDBE tal como descrito pelo censo anual de capitais estrangeiros realizado pelo BCB. Breves considerações finais encerram o artigo.

\section{CARACTERIZAÇÃO GERAL DO IDBE}

Em termos mundiais, o destino dos investimentos no exterior tem sido principalmente o setor terciário. Em 1990, esse setor concentrava 47\% do estoque de IDE mundial, contra 44\% do setor secundário e 9\% do primário. Já em 2002, a participação do terciário passou para $67 \%$ do estoque total, contra $29 \%$ do secundário e $4 \%$ do primário. Os números para o Brasil corroboram esta tendência. Segundo dados dos censos do BCB, até 2003, o setor primário manteve uma participação quase irrelevante no estoque de capitais brasileiros no exterior, fechando este último ano com $0,6 \%$. A partir de então, nota-se uma recuperação na participação do setor, que fechou 2004 com 1,9\% e 2005 com 5,2\%. O setor secundário, por sua vez, perdeu bastante representatividade nos últimos anos, passando de $8,0 \%$ do total dos investimentos brasileiros no exterior para apenas 3,7\% entre 2001 e 2005. O setor terciário, por sua vez, alcançou, em 2005, 91,1\% 
do total do IDBE. À parte as atividades financeiras e holdings, a estrutura do estoque do capital restante indica que investimentos relacionados ao comércio e apoio às exportações, uma atividade tipicamente concentradora de IDE nos países em desenvolvimento, constituiu também o mais importante item no Brasil.

Não houve muita variação quanto aos ramos de atividade que mais receberam investimentos diretos nos últimos anos recenseados. Elas estiveram quase sempre ligadas ao setor terciário, como mostra a Tabela 2. Verifica-se, entre as cinco principais atividades, uma grande discrepância em relação aos volumes investidos: as três primeiras categorias lideram com vantagem, concentrando cerca de $85 \%$ do total de investimento no período.

Tabela 2

IDE superior a 10\% - Principais atividades receptoras

\begin{tabular}{l|rrrrr}
\multicolumn{1}{c}{ em US\$ milhões } \\
\hline Total & $\mathbf{2 0 0 1}$ & $\mathbf{2 0 0 2}$ & $\mathbf{2 0 0 3}$ & $\mathbf{2 0 0 4}$ & $\mathbf{2 0 0 5}$ \\
Serviços Prestados Principalmente às Empresas & $\mathbf{4 2 . 5 8 4}$ & $\mathbf{4 3 . 3 9 7}$ & $\mathbf{4 4 . 7 6 9}$ & $\mathbf{5 4 . 0 2 7}$ & $\mathbf{6 5 . 4 1 8}$ \\
Intermediação Financeira & 14.306 & 13.945 & 17.811 & 20.013 & 23.639 \\
Atividades Auxiliares da Intermediação Financeira, Seguros e Previdência & 13.171 & 15.083 & 13.856 & 15.137 & 17.234 \\
Complementar & 7.536 & 8.469 & 8.477 & 12.887 & 14.898 \\
Comércio Por Atacado e Representantes Comerciais e Agentes do Comércio & 1.724 & 1.806 & 1.868 & 2.235 & 2.871 \\
Extração de Petróleo e Serviços Relacionados & 1.556 & 78 & 182 & 566 & 2.808 \\
Construçăo & 1.229 & 1.504 & 695 & 544 & 568 \\
\hline
\end{tabular}

Fonte: Banco Central do Brasil

Em relação ao destino, Argentina, Estados Unidos, Espanha, Portugal e Uruguai concentram quase a totalidade do IDBE que não é direcionado para paraísos fiscais, conforme a Tabela 3. Em 2001, os investimentos brasileiros diretos na Argentina corresponderam a 3,8\% do total do IDBE no período, e variaram pouco até 2005 , quando totalizaram 3,2\% do investimento. O IDBE na Espanha, que representava, em 2001, 3,9\% do estoque total naquele ano, chegou a $6,8 \%$ em 2002, mas apresentou uma pequena queda a partir de então, e em 2005 representava 5,1\% do total. Os Estados Unidos detinham cerca de 3,3\% do total do IDBE no ano de 2001 e, mantendo a tendência crescente, responderam por $6,4 \%$ do IDBE em 2005. Portugal diminuiu sua participação no estoque de capitais brasileiros no exterior, que em 2002 foi de $2,7 \%$, recuando para $1,3 \%$ em 2005. Já o Uruguai, que em 2001 concentrava 7,3\% do estoque de IDBE, chegou a 2005 com apenas $2,7 \%$ do capital brasileiro no exterior. 
Tabela 3

Investimento Direto no Exterior

\begin{tabular}{|c|c|c|c|c|c|c|c|c|c|c|}
\hline & & & & & & & & & & S\$ milhöes \\
\hline & 2001 & 2002 & 2003 & 2004 & 2005 & 2001 & 2002 & 2003 & 2004 & 2005 \\
\hline Paraísos Fiscais* & 30.797 & 31.505 & 30.092 & 29.810 & 31.861 & 5.129 & 9.022 & 8.440 & 13.628 & 12.484 \\
\hline Estados Unidos & 1.401 & 1.830 & 2.100 & 2.552 & 4.163 & 134 & 280 & 193 & 264 & 176 \\
\hline Uruguai & 3.121 & 1.547 & 2.810 & 1.657 & 1.748 & 482 & 693 & 831 & 676 & 621 \\
\hline Portugal & 697 & 1.186 & 1.066 & 945 & 864 & 37 & 15 & 13 & 22 & 11 \\
\hline
\end{tabular}

Fonte: Banco Central do Brasil

* São considerados: Antilhas Holandesas, Antígua e Barbuda, Ilhas Bahamas, Ilhas Barbados, Bermudas,

Ilhas Cayman, Ilha Madeira, Panamá e Ilhas Virgens

Apenas cinco países - Espanha, Estados Unidos, Países Baixos, França e Chile - concentram cerca de $80 \%$ do estoque de investimento na Argentina. Entre os sul-americanos, o Chile é o único país que tem uma participação relevante e relativamente constante no fluxo de investimento para a Argentina, e juntamente com o Brasil é responsável pela quase totalidade de investimentos sul-americanos realizados no país. No período 1997-2000, os investimentos brasileiros na Argentina respondiam por cerca de 5,7\% de todo IDE que o país recebeu de acordo com Direção Nacional de Contas Internacionais, do Ministério da Economia argentino - ficando atrás apenas de Estados Unidos, Espanha, Canadá e Chile. Neste período, o Brasil investiu na Argentina cerca de US\$ 1.582 milhões, destacando-se os projetos realizados em conjunto com capitais nacionais. A indústria manufatureira recebeu $37 \%$ dos investimentos brasileiros no período, e o setor de infra-estrutura e comunicação liderou com $44,2 \%$ dos investimentos recebidos. Em 2002, o Brasil foi o maior investidor internacional na Argentina, quando as petrolíferas Pérez Compac e a Pecom Energia foram vendidas para a brasileira Petrobras. Conforme estimativas apresentadas em relatório do Ministério da Economia e Produção, até a metade de 2004, o Brasil teria investido cerca de US\$ 44 milhões em formação de capital, 0,63\% do total recebido pelo país no ano. Esses investimentos foram destinados, sobretudo, aos setores de infra-estrutura (US\$16 milhões) e comércio e serviços (US\$ 16 milhões).

Já os investimentos estrangeiros que entram em Portugal têm origem principalmente nos comunitários europeus. De acordo com a Agência Portuguesa para o Investimento, entre janeiro de 1996 e julho de 2004, os países da UE foram responsáveis por cerca de $84 \%$ dos investimentos que ingressaram em Portugal. No mesmo período, os Estados Unidos contabilizavam 3,4\% de todo o IDE no país, e o Brasil, 2,8\%. A maioria dos investimentos brasileiros no país estava concentrada em atividades financeiras, como bancos, seguros e serviços prestados a companhias, e completando quase a totalidade de investimentos, vinham aqueles destinados à indústria de transformação. 
Os investimentos brasileiros na Espanha eram quase insignificantes até 2001, quando chegaram a representar 3,8\% do total recebido pelo país. Em 2002, a participação brasileira caiu para aproximadamente $1,5 \%$ do total investido no país, que tem como principal investidor individual os Estados Unidos e, em termos de blocos regionais, os países da UE. Os investimentos brasileiros na Espanha são concentrados no setor de gestão de sociedades e holdings de valores, conforme dados obtidos junto à Direção Geral de Comércio e Investimentos do Ministério da Indústria, Comércio e Turismo. De acordo com os dados oficiais, o fluxo de investimento brasileiro bruto efetivo total (investimentos registrados descontadas as aquisições de outros não residentes e reestruturações de grupos estrangeiros) recuou consideravelmente em 2003, totalizando cerca de 2,2 milhões de euros. Três setores concentraram quase todo o investimento brasileiro do período: hotelaria, empresas ligadas a atividades financeiras e atividades imobiliárias.

Em relação aos Estados Unidos, apesar de ser o país em que o Brasil realiza a maior parte de seus investimentos no exterior - exceto se compararmos com os paraísos fiscais - , a representatividade desses investimentos é muito baixa, devido ao grande fluxo recebido pelo país. No final de 2005, os Estados Unidos concentravam quase $6,5 \%$ de todo o estoque de IDBE. Nesse mesmo ano, o Brasil foi responsável por cerca de 1,5\% do fluxo total de IDE para os Estados Unidos, segundo o BEA (Bureau of Economic Analysis).

\section{Estratégias dos grupos industriais}

Ao discutir os desafios e oportunidades para a indústria brasileira dos anos 90, Ferraz, Kupfer \& Haguenauer (1996) e Ferraz, Haguenauer \& Kupfer (1997) subdividiram-na em quatro grupos: commodities, bens duráveis, tradicionais e difusores de progresso técnico. Na sua visão, o grupo composto por produtores de commodities busca competitividade em vantagens de custo, através da expansão das escalas produtivas, padronização dos processos, e redução dos índices de consumo de matérias-primas. Para viabilizar investimentos de longo prazo, buscam fontes externas e internas, e têm um nível de sofisticação na estratégia financeira elevado. No Brasil, prevalecem as grandes empresas nacionais, e há também algumas estrangeiras.

O grupo produtor de commodities apresenta níveis elevados de eficiência produtiva e conformidade dos produtos, sendo caracterizado por um desempenho positivo no comércio exterior. São, no entanto, empresas com baixo esforço tecnológico. Para os autores, apesar deste grupo ter uma baixa proporção de investimento direto no exterior, ele era o único que apresentava tendência crescente de realização de tais investimentos, e o advento do MERCOSUL deveria contribuir positivamente nesse sentido.

O grupo de bens duráveis, por sua vez, apresenta o ritmo de transformação 
mais acelerado na indústria brasileira, marcado pelo processo de modernização e regionalização produtiva. Esse grupo é composto, em sua maioria, por subsidiárias de grupos internacionais, e seu padrão setorial é caracterizado por empresas de grande porte, que têm no preço e na eficiência da assistência técnica os fatores determinantes do sucesso competitivo. Como tendência de futuro, os autores acreditavam que haveria um incremento das relações comerciais com clientes e fornecedores fora do país, ou seja, parte da produção seria deslocada para fora da fronteira brasileira. Os investimentos diretos deste grupo no exterior seriam, portanto, baixos e sem perspectiva de recuperação.

O grupo tradicional é composto essencialmente pelas indústrias alimentares, pelos setores do complexo têxtil/vestuário/calçados e pela indústria do mobiliário, e é caracterizado por uma heterogeneidade competitiva bastante acentuada. Este grupo, de acordo com Ferraz, Haguenauer \& Kupfer (1996; 1997), apresentava forte probabilidade de crescimento das importações, exportações e investimentos no país. Em relação aos investimentos no exterior, porém, acreditavam que este poderia ocorrer de forma esporádica, especialmente por ação das empresas líderes, que também concentrariam parte significativa das vendas externas.

O grupo de difusores de progresso técnico reúne os produtores de bens de capital, e é bastante heterogêneo em termos de base técnica e mercado de atuação, mas tem em sua matriz industrial a função comum de elevar a produtividade das demais atividades econômicas. As empresas desse setor têm papel central no processo de desenvolvimento industrial, na medida em que ditam, em grande parte, o ritmo de incremento da produtividade do conjunto da economia. De acordo com os autores, este grupo apresenta níveis crescentes de importações, exportações e investimento direto no Brasil, porém sua tendência de investimento direto no exterior era considerada baixa e estável.

Em resumo, Ferraz, Kupfer \& Haguenauer (1996) e Ferraz, Haguenauer \& Kupfer (1997) acreditam que a internacionalização patrimonial, produtiva e comercial da indústria brasileira é uma de suas características mais marcantes, a ponto de nenhum outro país de nível de densidade e complexidade industrial similar apresentar uma relação capital local/capital estrangeiro tão baixa. Mais importante ainda é que os autores apontavam que a tendência era a continuidade e não a ruptura de tal trajetória.

Confrontando as perspectivas apontadas pelos autores com os dados obtidos junto aos últimos censos, verificamos que, apesar de o grupo commodities ${ }^{2}$ ter maior representatividade nos investimentos diretos no exterior, essa represen-

\footnotetext{
${ }^{2}$ Aqui se tentou classificar cada um dos itens que compõem o setor secundário na classificação do Banco Central em uma das quatro categorias sugeridas por Ferraz, Kupfer \& Haguenauer (1996) e Ferraz, Haguenauer \& Kupfer (1997).
} 
tatividade vem caindo em relação ao total do IDBE. Em 2001, este grupo era responsável por cerca de $64 \%$ dos investimentos realizados pelo setor secundário no exterior (ou 3,3\% do total). Em 2005, sua participação era de apenas 46,2\% do IDBE realizado no setor secundário, e 1,3\% do total. Esse forte recuo contraria a previsão dos autores de que o grupo de commodities apresentaria investimentos crescentes no exterior. A tendência à redução de investimentos no exterior se verifica tanto em termos percentuais, como em termos absolutos: em 2001 foram US\$ 1.390 milhões investidos, contra US\$ 823 milhões em 2005.

Quanto aos demais grupos, classificados pelos autores como de investimento baixo e estável no exterior, a maior surpresa foi o desempenho do grupo tradicional, que em 2001 representava 15,8\% dos investimentos que o setor secundário realizou no exterior, chegando a $34,5 \%$ em 2005. Porém, este bom desempenho deve-se menos a um surto de investimento por parte do grupo de produtos tradicionais do que ao menor volume de investimentos realizado pelo secundário. $\mathrm{Na}$ verdade, a participação do grupo produtor de bens tradicionais em relação ao total dos investimentos no exterior subiu apenas de $0,8 \%$ em 2001 , e $0,9 \%$ em 2005. O grupo classificado como difusor de progresso técnico apresentou pouca variação no volume de investimento nos três anos analisados, tanto em valores absolutos como em proporção ao investimento realizado pelo secundário. Em 2001, o grupo realizou 11,3\% do IDBE do setor secundário (0,6\% do total); e, em 2005, $14 \%$ (e $0,4 \%$ do total). Por fim, o grupo produtor de bens duráveis teve uma participação nos investimentos do setor secundário no exterior baixa e decrescente. Em 2001 o grupo foi responsável por 8,9\% do investimento realizado pelo secundário $(0,5 \%$ do total), mas em 2005 sua participação no IDBE direcionado ao setor secundário foi de cerca de $5,2 \%$, representando apenas $0,1 \%$ do total do IDBE.

\section{O IDE dos países em desenvolvimento}

A internacionalização da produção foi intensificada pelo processo da globalização, através dos fluxos de IDE. Segundo a UNCTAD (2002), para o período 1996-2000, enquanto os fluxos de IDE realizados cresceram 37\% ao ano, as exportações mundiais aumentaram apenas $4,2 \%$ ao ano. O crescimento da produção internacionalizada é uma resposta às mudanças no ambiente econômico mundial, caracterizado pelas mudanças tecnológicas, pela liberalização política e pela competição crescente. O processo de internacionalização, no entanto, não foi homogêneo no que diz respeito à participação dos países. Estima-se que o estoque de IDE realizado pelos países desenvolvidos, entre 1995 e 2001, seja oito vezes superior ao realizado no mesmo período pelos países em desenvolvimento.

Para Alem \& Cavalcanti (2005), a experiência internacional mostra que as políticas públicas de apoio à internacionalização das empresas devem incluir elementos como: i) liberalização das restrições aos investimentos diretos no exterior, já 
que implicam saída de divisas; ii) a criação de instrumentos internacionais que facilitem e protejam os investimentos no exterior; iii) informação e assistência técnica; iv) incentivos fiscais; v) mecanismos de seguros para os investimentos, e vi) financiamento. Em diversos países desenvolvidos, além dos serviços de informação e assistência técnica, o apoio financeiro também está disponível. Os recursos são distribuídos, em grande medida, por instituições de desenvolvimento para o apoio aos projetos de investimento diretos. Em relação aos países em desenvolvimento, o apoio à internacionalização das empresas tem tido como metas principais o aumento da competitividade e a expansão do comércio, sendo que políticas mais sistemáticas de apoio à internacionalização são observadas nos países asiáticos.

O IDBE é relativamente baixo, se comparado ao de outros países em estágio semelhante de desenvolvimento, especialmente os países do Sudeste Asiático, conforme a Tabela 4. Ainda que bastante inferior ao realizado pelos países desenvolvidos, o IDE realizado pelos países em desenvolvimento aumentou substancialmente nos últimos anos, e sua representatividade no IDE total passou de pouco mais de $8 \%$, em 1990, para cerca de $12 \%$ em 2005. Mais impressionante foi o desempenho dos países asiáticos, que mais do que dobraram sua participação no período, e atualmente respondem por cerca de $8,2 \%$ do IDE total. A participação dos países latino-americanos, ao contrário, apresentou uma ligeira tendência à queda, e, em 2005, esses países detinham apenas 3,2\% do total.

Tabela 4

Estoque de IDE realizado pelos países em desenvolvimento - 1990, 2000 e 2005

\begin{tabular}{|c|c|c|c|c|c|c|}
\hline \multirow[b]{2}{*}{ País } & \multicolumn{3}{|c|}{ US\$ Milhões } & \multicolumn{3}{|c|}{$\begin{array}{c}\text { Participação dos países } \\
\text { no total - em \% }\end{array}$} \\
\hline & 1990 & 2000 & 2005 & 1990 & 2000 & 2005 \\
\hline Total Mundo & 1.791 .092 & 6.471 .435 & 10.671 .889 & - & - & \\
\hline Países desenvolvidos & 1.642 .187 & 5.578 .341 & 9.271 .932 & $91,7 \%$ & $86,2 \%$ & $86,9 \%$ \\
\hline Países em desenvolvimento & 148.715 & 871.040 & 1.273 .612 & $8,3 \%$ & $13,5 \%$ & $11,9 \%$ \\
\hline América Latina & 60.598 & 211.726 & 345.320 & $3,4 \%$ & $3,3 \%$ & $3,2 \%$ \\
\hline Argentina & 6.057 & 21.141 & 22.633 & $0,3 \%$ & $0,3 \%$ & $0,2 \%$ \\
\hline Brasil & 41.044 & 51.946 & 71.556 & $2,3 \%$ & $0,8 \%$ & $0,7 \%$ \\
\hline Chile & 154 & 11.154 & 21.286 & $0,0 \%$ & $0,2 \%$ & $0,2 \%$ \\
\hline México & 2.672 & 8.273 & 28.040 & $0,1 \%$ & $0,1 \%$ & $0,3 \%$ \\
\hline Ásia & 68.179 & 614.307 & 873.917 & $3,8 \%$ & $9,5 \%$ & $8,2 \%$ \\
\hline China & 4.455 & 27.768 & 46.311 & $0,2 \%$ & $0,4 \%$ & $0,4 \%$ \\
\hline Cingapura & 7.808 & 56.766 & 110.932 & $0,4 \%$ & $0,9 \%$ & $1,0 \%$ \\
\hline Hong Kong & 11.920 & 388.380 & 470.458 & $0,7 \%$ & $6,0 \%$ & $4,4 \%$ \\
\hline República da Coréia & 2.301 & 26.833 & 36.478 & $0,1 \%$ & $0,4 \%$ & $0,3 \%$ \\
\hline Taiwan & 30.356 & 66.655 & 97.293 & $1,7 \%$ & $1,0 \%$ & $0,9 \%$ \\
\hline
\end{tabular}

Fonte: UNCTAD - WIR 2006 
De acordo com a UNCTAD (2004), se os investimentos no exterior forem vistos em relação à formação bruta de capital fixo, alguns países em desenvolvimento - Cingapura, Hong Kong e Taiwan — superaram alguns desenvolvidos (Alemanha, Japão e Estados Unidos). Vale destacar ainda que, nos últimos quinze anos, os fluxos anuais de investimento direto dos países em desenvolvimento cresceram mais rapidamente do que aqueles realizados pelos países desenvolvidos. Especialmente os investimentos originados na Ásia e em alguns países da África têm crescido muito nos últimos anos, enquanto os de origem latino-americana sofreram um processo de estagnação.

Segundo o mesmo estudo, em 2003, o Brasil já era o país latino-americano com o maior estoque de investimento direto no exterior - US\$ 55 bilhões - e o quarto no ranking mundial dos países em desenvolvimento, ficando atrás de Hong Kong, China, Cingapura e Taiwan. Como porcentagem da formação bruta de capital fixo, porém, o índice brasileiro fica em $0,2 \%$, um oitavo da média latinoamericana, e um décimo da média do conjunto de PEDs. Já como proporção do PIB, os investimentos brasileiros também se encontram em um nível médio inferior ao dos demais países em desenvolvimento (11\% do Brasil contra $12 \%$ da média dos PEDs) e bem abaixo da média dos países do Sul,Leste e Sudeste Asiático $(16 \%)$.

\section{INTERNACIONALIZAÇÃO DAS EMPRESAS BRASILEIRAS: ELEMENTOS CONCEITUAIS E ESTUDOS EMPÍRICOS}

As empresas brasileiras apresentam uma baixa relação entre exportações e PIB, baixo coeficiente médio de exportação na indústria e uma elevada concentração das exportações em um pequeno número de firmas e produtos. Uma empresa pode fazer do investimento externo um instrumento de apoio às exportações, ou seja, realizar o investimento para ampliar e fortalecer as vendas em um dado mercado. Tais investimentos podem ser tanto de comercialização (abertura de escritórios comerciais, armazéns, centros de distribuição) quanto produtivos. Nos países em desenvolvimento, a grande maioria das firmas exportadoras não tem investimentos no exterior, sejam eles produtivos ou de comercialização. As empresas brasileiras corroboram esta constatação. A maior parte das firmas exportadoras não passou da fase de simples exportação, e mesmo aquelas que apresentam um elevado grau de internacionalização possuem baixo nível de investimento no exterior.

Vários estudos foram realizados para tentar compreender o processo, as motivações e os desafios das empresas dos países em desenvolvimento que optam pela internacionalização de suas atividades produtivas. Chudnovsky \& Lopez (1999), por exemplo, acreditam na existência de dois fatores condicionantes do surgimento de multinacionais nos países em desenvolvimento: a aprendizagem 
tecnológica, que permite à empresa desenvolver vantagens de propriedade específicas, e a condição do país como receptor ou emissor de investimento estrangeiro direto, na medida em que seu desenvolvimento econômico permitiria a expansão das vantagens proprietárias das firmas. Segundo os autores, as firmas de países em desenvolvimento internacionalizam suas atividades produtivas especialmente em países de nível semelhante de desenvolvimento, sobretudo em uma etapa inicial de internacionalização de suas atividades. Com o amadurecimento na condução de atividades de negócios no exterior, as empresas eventualmente expandiriam rumo aos países mais desenvolvidos.

Dunning (1988) e Dunning, Hoesel \& Narula (1997) também relacionam as atividades de internacionalização das firmas dos países em desenvolvimento ao investimento direto externo recebido e emitido pelo país. Os investimentos diretos no país, ao contribuirem para o desenvolvimento de ativos específicos, colaboram com a internacionalização das firmas domésticas. Para os autores, há uma série de etapas no processo de internacionalização de uma firma de PED; na primeira, o país é muito pouco desenvolvido para atrair investimentos e as firmas locais não têm nenhum tipo de vantagem proprietária para investir no exterior; nas duas últimas, as firmas já teriam desenvolvido vantagens proprietárias específicas, os setores emissores de investimentos seriam mais capital e conhecimento intensivos, e os países de destino dos investimentos dependeriam exclusivamente das estratégias das multinacionais locais.

Para Cantwell \& Tolentino (1990), por sua vez, as multinacionais com origem em países em desenvolvimento têm tecnologias genuinamente inovadoras, devido à transformação da estrutura industrial que se processou em um conjunto de países, através de distintas formas de aprendizagem e da própria internacionalização. Segundo os autores, essas vantagens proprietárias levariam as firmas dos PEDs a expandir suas atividades não apenas para países de um mesmo nível de desenvolvimento, mas também para países desenvolvidos, em setores tecnologicamente mais complexos.

A decisão de uma firma de realizar um investimento em determinado destino das exportações, com o intuito de ampliar e fortalecer as vendas nesse mercado, depende de fatores econômicos, mas também está relacionada com as características de organização da própria firma. As diferenças entre os mercados (o doméstico e o novo mercado a ser conquistado) geram incertezas sobre os resultados dos investimentos que só podem ser diminuídas pelo conhecimento da outra cultura.

A evolução e as características do investimento brasileiro no exterior foram estudadas por alguns autores a partir da década de 70, na tentativa de detectar as motivações, e as restrições ou dificuldades que as empresas de capital nacional encontraram para avançar no processo de internacionalização. Dias (1994), Goulart, Brasil \& Arruda (1994) e Lopez (1999) concordam que houve diversas fases no processo, com diferenças nas especificidades setoriais, nas motivações estraté- 
gicas, nas modalidades de financiamentos e nas formas de implementação do investimento. Concordam, ainda, que os determinantes dessas diferentes fases estiveram fortemente vinculados ao contexto macroeconômico do país, portanto, a estabilização econômica ou o processo de integração regional tiveram impacto considerável na internacionalização das firmas brasileiras. Enquanto nos países da América Latina a internacionalização das empresas parece estar estreitamente relacionada ao contexto macroeconômico, nos países asiáticos ela esteve muito mais associada a variáveis da estrutura da economia e das características das firmas.

Em pesquisa conduzida pelo BNDES (1995) observou-se que, à diferença dos anos 70, quando só grandes empresas - com faturamento acima de US\$ 500 milhões - tinham investimentos no exterior, na década de 80 havia uma participação significativa daquelas com faturamento entre US\$ 200 milhões e US\$ 500 milhões e daquelas com faturamento inferior a US\$ 100 milhões. O estudo também constatou um aumento no número de subsidiárias instaladas no exterior, especialmente de subsidiárias produtivas. A participação da América do Sul como localização dos investimentos, e a diversificação dos setores da indústria de transformação investidores também aumentaram.

O estudo do BNDES (1995) contou com as respostas de 30 grandes grupos nacionais, que haviam instalado 101 subsidiárias no exterior entre o início da década de 70 e 1994. Essas subsidiárias estavam concentradas nos setores de mecânica, material de transporte e construção, e foram, em sua maioria, resultado de compras ou de associações com firmas existentes. A pesquisa sugere que há uma relação entre a forma de implementação e o tipo de investimento a ser realizado: quando se trata de unidades produtivas, as firmas preferem adquirir as já existentes, ao passo que quando se trata de implementar unidades comerciais ou investimentos não relacionados à produção, as empresas preferem novas unidades. O fortalecimento do poder de competição, graças à proximidade com o mercado consumidor, foi considerado a principal motivação para as empresas internacionalizarem suas unidades, seguido pela capacidade de suprir o mercado regional e pelas novas oportunidades de investimentos possibilitadas pela integração regional. Quanto às maiores dificuldades, os problemas de financiamento doméstico e as diferenças culturais foram os fatores mais lembrados pelas empresas.

Conforme Goulart, Brasil \& Arruda (1994), na primeira metade da década de 90 , a abertura econômica estimulou um processo de reestruturação empresarial e houve, simultaneamente, uma nova fase de internacionalização exportadora das empresas manufatureiras. A diversificação do porte das empresas com investimentos no exterior, já apontada pela pesquisa do BNDES para a década de 80 , acentuou-se ainda mais na década seguinte, e a localização dos investimentos concentrou-se nos países do Cone Sul (mais de 50\% do total investido no período). Em ambos os períodos estudados, a construção foi o setor individual com 
maior número de instalações de unidades no exterior. A proporção de empresas de faixas menores de faturamento aumentou, fazendo com que o grupo respondesse por $53 \%$ dos investimentos realizados no exterior entre 1990 e 1994. Em meados da década de 90 , graças à estabilização econômica, que ampliou sobremaneira o mercado doméstico, e à apreciação da taxa de câmbio real, a expansão internacional das empresas sofreu um desestímulo, especialmente nos dois primeiros anos do programa de estabilização.

O trabalho de Dias (1994), por sua vez, contou com uma amostra de 22 empresas, selecionadas entre as 500 maiores do Brasil, que tinham realizado investimentos no exterior entre 1989 e 1991. Para quase todo o grupo, a receita com as exportações representava entre $10 \%$ e $20 \%$ da receita total. As empresas da amostra também apresentavam elevado grau de desenvolvimento tecnológico. Conforme o estudo, uma das principais razões para a realização de investimentos no exterior para uma firma era a necessidade de estabelecer parcerias com as empresas compradoras, em função das mudanças nas relações ocorridas entre as empresas e seus fornecedores. Nesses casos, a instalação de uma subsidiária no exterior era uma tentativa de solucionar os problemas tecnológicos e de especificação do produto. Conforme as necessidades de seus clientes, as empresas optaram por estabelecer no exterior escritórios comerciais ou acordos de pesquisa e desenvolvimento tecnológico, pela realização de joint ventures com empresas locais, ou pela instalação de plantas de produção ou unidades de manutenção e reparos de peças. Grande parte desses investimentos estava localizada nos EUA, na Argentina e outros países da América Latina.

A pesquisa de Brasil, Leonel, Arruda \& Goulart (1996) contou com dados reunidos pela Fundação Dom Cabral e informações jornalísticas. Segundo os pesquisadores, entre 1990 e 1994, 160 empresas brasileiras haviam realizado algum tipo de investimento produtivo ou instalado escritórios no exterior - perfazendo um total de 285 empreendimentos. Essa amostra foi selecionada e, das 160 empresas, 57 responderam à pesquisa. Os fatores determinantes da internacionalização mais citados foram a necessidade de estar próximo ao cliente - para ajustar a especificação do produto, melhorar a logística de fornecimento e oferecer aos clientes serviços de assistência técnica - assim como previu a pesquisa de Dias (1994), a conquista de novos mercados e o acesso a tecnologias. A redução da distância cultural em relação aos mercados em que se pretende investir, e a melhoria na capacidade de estabelecer alianças e parcerias para conquistar o mercado externo foram citadas como elementos fundamentais na determinação do processo de internacionalização das firmas. Quanto aos maiores obstáculos ao processo de internacionalização, aspectos burocráticos e de legislação brasileiros e a restrição a financiamentos foram os mais destacados. As principais dificuldades citadas na gestão das unidades no exterior foram o acesso à informação, a dificuldade na identificação de parceiros, a carência de recursos financeiros, e a falta de prática em negócios em outros países. 
Já a pesquisa conduzida por Iglesias \& Veiga (2002), ao contrário das anteriores, que continham na amostra apenas empresas com investimentos no exterior, analisou um conjunto de empresas exportadoras, de diversos tamanhos e freqüências de exportação, e buscou determinar algumas características de decisões de investimentos passadas, intenções de investimento ou decisão de não investir no exterior. As micro e pequenas empresas (até 99 empregados) representavam $46 \%$ da amostra, as de porte médio (de 100 a 499 empregados), 33\%, e as grandes empresas (mais de 500 empregados), $21 \%$. Classificadas de acordo com seu desempenho exportador, as permanentes (que exportaram todos os anos entre 1994 e 2000) representavam 19,6\% da amostra, que também era composta por exportadoras esporádicas e iniciantes (que exportaram até três anos entre 1994 e 2000), sendo que as iniciantes não exportaram antes de 1997.

Do total da amostra, apenas $20 \%$ das empresas possuíam algum tipo de investimento no exterior - seja para apoiar a comercialização dos produtos feitos no Brasil, seja para produzir no exterior - , mas esta proporção quase dobrava $(38,1 \%)$ quando se consideravam apenas as firmas grandes. Também se constatou que, quanto maior a freqüência exportadora da firma, maior era a possibilidade dessa empresa investir no exterior. Quanto à relação entre a composição do capital da empresa e a realização de investimentos no exterior, verificou-se que aquelas que tinham alguma participação estrangeira na composição de seu capital tinham uma proporção mais elevada de investimentos no exterior. O conjunto das firmas grandes e exportadoras permanentes apresentou uma proporção maior de investimentos no exterior, porém, mais de $80 \%$ da firmas nacionais que apresentaram atividade exportadora permanente não tinham qualquer investimento no exterior.

De acordo com a pesquisa, cerca de $73 \%$ de todos os investimentos realizados por firmas brasileiras no exterior estavam localizados nos Estados Unidos ou na Argentina, e quase $85 \%$ em atividades de comércio e distribuição de produtos. Os investimentos em unidades produtivas representavam $12 \%$ do total e estavam concentrados nos setores têxtil, químico, de metalurgia básica e veículos. O principal investimento das firmas de capital nacional estava em representações comerciais $(42,7 \%)$, seguido pelo investimento em canais de distribuição $(22,7 \%)$. As principais motivações citadas foram a necessidade de logística, o costume de comprar de empresas já instaladas no país, e a necessidade de acompanhar as demandas do mercado consumidor.

Assim como já apontado em estudos anteriores, as dificuldades de obtenção de informações sobre mercados e regulação dos investimentos no exterior, e as dificuldades de financiamento foram os obstáculos à internacionalização mais citados. Apesar das dificuldades apontadas por algumas firmas, outras afirmam que não internacionalizaram suas atividades simplesmente porque não sentiram necessidade de fazê-lo (40\%). Nesses casos, portanto, a não realização de inves- 
timentos no exterior está ligada a estratégias e características das firmas e não a restrições externas a elas.

Em geral, discute-se muito a respeito dos efeitos dos investimentos diretos no exterior e a conveniência ou não de algum tipo de política de incentivo. Os argumentos mais comuns dos que se posicionam contra o incentivo a investimentos externos são o deslocamento de emprego para o exterior, redução das exportações, transferência de conhecimentos, redução da arrecadação tributária e menor taxa agregada de investimento na economia local. Apesar de muitos estudos na área, ainda há controvérsia e ambigüidade acerca dos resultados de investimentos no exterior. Esse investimento, ao mesmo tempo em que pode substituir as exportações, também pode gerar demanda de outros produtos domésticos, como bens de capital, bens intermediários ou serviços. O investimento no exterior pode, portanto, substituir exportações, mas, em contrapartida, estimular ou criar um novo comércio. O mais importante, porém, é que a não realização do mesmo pode significar perda de dinamismo para as empresas que disputam posições no ambiente internacional (tanto externa como internamente), ocasionando eventualmente impactos negativos sobre o nível de emprego e a competitividade da economia, e maior exposição aos riscos da economia nacional. De acordo com a UNCTAD (2004), em pesquisa realizada com países desenvolvidos, o efeito da criação de comércio normalmente supera o efeito substituição. Em relação à conta de capital e aos serviços de fatores, o impacto do investimento vai depender de vários aspectos, como a estrutura do financiamento do investimento no exterior ou a existência de risco cambial no país de origem do investimento.

\section{CONSIDERAÇÕES FINAIS SOBRE A INTERNACIONALIZAÇÃO PRODUTIVA DAS EMPRESAS BRASILEIRAS}

A promoção das atividades de internacionalização abre para o país a possibilidade de colocar suas empresas em uma posição mais significativa no cenário mundial. A internacionalização deve ser vista como um meio essencial para o aumento da competitividade internacional das empresas, promovendo o desenvolvimento dos países e facilitando: i) o acesso a recursos e mercados, e ii) a reestruturação econômica. Em linhas gerais, a internacionalização das empresas é importante para assegurar e expandir mercados para seus bens e serviços. $\mathrm{O}$ acesso a mercados maiores fortalece a competitividade das empresas multinacionais pelas economias de escala, efeitos de especialização de aprendizado e pelo fornecimento de uma maior base financeira para reinvestimentos e desenvolvimento tecnológico (Além \& Cavalcanti, 2005).

A opção por uma estratégia de inserção em mercados internacionais deve levar em conta os objetivos das empresas, além de dimensões estratégicas em relação a recursos e capacidades das mesmas, mas o fato é que atuar em variados 
mercados aumenta a capacidade de sobrevivência face às dificuldades impostas pelo ambiente altamente competitivo da atualidade. Os resultados obtidos dos censos de capital brasileiro no exterior do BCB serão nesta parte confrontados com aqueles das pesquisas analisadas no item anterior para avaliar uma possível alteração na composição do IDBE no intervalo de tempo coberto pela pesquisa.

Vale destacar, para o caso brasileiro que, apesar de parte significativa do IDBE ser realizada na Argentina, o país não segue fielmente a tendência apontada pelas abordagens apresentadas anteriormente, ou seja, os investimentos brasileiros não são realizados essencialmente em países de nível semelhante de desenvolvimento, mas, pelo contrário, em países desenvolvidos como Estados Unidos, Espanha e Portugal. O processo de internacionalização mostra assim que não tem necessariamente características evolutivas marcadas por etapas seqüenciais rígidas, mas, antes, apresenta peculiaridades características para cada empresa que decide se aventurar em novos mercados.

Não surpreendentemente, o destino dos investimentos brasileiros no exterior está intimamente relacionado com os países com os quais mantém fortes laços de comércio. Uma das explicações mais coerentes com esse fato é que as relações comerciais oferecem aos potenciais investidores um melhor conhecimento do mercado em que se pretende investir. Essa proximidade parece favorecer as relações e o conhecimento do mercado desses países, estimulando a penetração dos investimentos. Como a falta de informações sobre o mercado é considerada uma das maiores dificuldades das empresas na hora de avaliar a realização de um investimento, de acordo com a série de estudos e pesquisas abordados anteriormente, o processo de simples exportação parece ser uma experiência prévia pela qual as empresas que decidem investir no exterior devem passar.

Como já mencionado anteriormente, Argentina, Espanha, Estados Unidos e Portugal são os principais receptores de investimentos produtivos brasileiros. Com o primeiro, pode-se destacar, além da tradição comercial, a proximidade geográfica, e, ainda, a maior integração regional promovida pelo Mercosul. Estima-se que os investimentos nesse país só não sejam maiores por causa da instabilidade política, que caracteriza historicamente os países da América Latina e a fragilidade econômica, explicitada na recente crise que devastou a economia argentina. Os investimentos nesse país estão fundamentalmente concentrados em representações comerciais e canais de distribuição. Espanha e Portugal, além de serem destino de exportação, essencialmente de produtos manufaturados, são ainda fortes investidores no Brasil, fato que sugere a existência de uma relação entre os investimentos realizados por estrangeiros no Brasil e a realização do IDBE. Assim como a atividade exportadora permite um maior conhecimento do mercado em que se pretende iniciar atividades, os investimentos estrangeiros realizados no país dão aos potencias investidores nacionais pistas sobre o funcionamento do mercado do país que realiza os investimentos. A proximidade da rela- 
ção entre executivos e mesmo a análise das formas de organização e condução dos negócios é uma fonte rica de informações ao investidor.

Em relação às principais atividades receptoras de investimentos nos anos recenseados, no setor primário, o IDBE foi destinado majoritariamente à extração de petróleo e serviços relacionados, e à extração de produtos metálicos. No setor secundário, os investimentos se dirigiram especialmente para a fabricação de coque, refino de petróleo e elaboração de combustíveis, para a fabricação de produtos de metal (exceto máquinas e equipamentos) e para a fabricação de produtos alimentícios e bebidas. Confrontados com os dados dos últimos censos do $\mathrm{BCB}$, observa-se que, apesar de ter havido uma maior diversificação no que diz respeito aos ramos de atividades no exterior, a concentração em volume de capital investido acentuou-se consideravelmente no setor terciário, especialmente nas atividades de intermediação financeira e suas atividades auxiliares.

Segundo Além \& Cavalcanti (2005), o apoio do BNDES à internacionalização das empresas brasileiras esteve restrito até meados de 2002. ${ }^{3}$ Naquele ano foram aprovadas as diretrizes para o financiamento aos investimentos de empresas brasileiras no exterior, com o objetivo de orientar a criação de uma linha capaz de estimular a inserção e o fortalecimento das empresas brasileiras no mercado internacional, promovendo o incremento das exportações. Embora aprovada, a linha de financiamento permaneceu em estágio embrionário. No final de 2003 foi criado um grupo de trabalho para examinar o tema. O grupo realizou visitas a empresas e realizou algumas constatações: (i) mesmo as companhias mais avançadas em seu processo de expansão no exterior mostraram ter necessidades financeiras, operacionais ou técnicas para continuar a expandir suas operações internacionais; (ii) entre as modalidades de investimento consideradas importantes para ampliar a presença internacional das empresas estão a criação de bases no exterior, especialmente para gestão de estoque, e iniciativas voltadas para o desenvolvimento das vendas locais, assistência técnica e promoção comercial, a fim de garantir melhor acesso e condições competitivas nos mercados consumidores.

Apesar da pequena representatividade das empresas brasileiras entre as maiores dos países em desenvolvimento em termos de ativos no exterior - apenas 3 entre as 50 maiores -, o Brasil parece vir caminhando a passos relativamente firmes rumo à internacionalização de suas empresas. O país conseguiu se destacar nos últimos anos como um dos principais investidores entre os emergentes, o que sinaliza a percepção doméstica de que a inserção competitiva no mercado externo faz parte de uma receita de sobrevivência para boa parte das firmas em um contexto de mercados com cada vez menos restrições à entrada de capitais estrangeiros.

\footnotetext{
${ }^{3}$ Tratava-se de financiamentos realizados mediante operações de renda variável, nas quais o incentivo aos investimentos no exterior acontecia de forma indireta (Além \& Cavalcanti, 2005).
} 
Caso fossem disponibilizados pelo Banco Central os dados desagregados relativos aos censos anuais de capitais brasileiros no exterior, seria então possível o desenvolvimento de uma avaliação adequadamente detalhada desse processo de internacionalização produtiva das empresas nacionais. Especificamente, seria eventualmente possível a realização de uma análise dos fluxos e estoques de IDBE em termos de i) tamanho, localização e composição (fluxos e estoques, por país de recepção, por setor e subsetor), ii) determinantes (internos e externos, em níveis micro e macro) e iii) desempenho (parcela do mercado local em termos de produção, emprego e rentabilidade, nível de produtividade e de transferência tecnológica, remessas de lucros e dividendos, reinvestimentos, exportações líquidas, comércio intrafirma). Além disso, um desdobramento natural dessa avaliação seria uma análise em nível de políticas governamentais de estímulo a essa internacionalização, para cujo encaminhamento efetivo a experiência internacional comparada se revelaria, mutatis mutandis, especialmente valiosa.

\section{REFERÊNCIAS BIBLIOGRÁFICAS}

ALÉM, A. C., e C. E. CAVALCANTI (2005) “O BNDES e o Apoio à Internacionalização das Empresas Brasileiras: Algumas Reflexões”. Revista do BNDES,. 12 (24): 43-76, dez. 2005.

ARGENTINA - Ministerio de Economía e Producción, Dirección Nacional de Cuentas Internacionales, (2001). http://www.mecon.gov.ar/cuentas/internacionales/

BNDES (1995). Caracterização do Processo de Internacionalização de grupos econômicos privados brasileiros. Rio de Janeiro, nov. 1995 (Série Pesquisas Empresariais, 1)

BRASIL, H.V., J.N. LEONEL, C. ARRUDA, e L. GOULART (1996) Pesquisa de campo sobre a internacionalização das empresas brasileiras. In: BRASIL, H.V. \& ARRUDA, C. (eds) Internacionalização das empresas brasileiras. Rio de Janeiro: Qualitymark, 1996

CANTWELL, J. e E. TOLENTINO (1990) Technological accumulation and Third World Multinationals. University of Reading, 1990

CHUDNOVSKY, D. e A. LOPEZ, eds. (1999) Las multinacionales latinoamericanas: sus estrategias en un mundo globalizado. Buenos Aires: Fondo de Cultura Económica.

DIAS, V. V.(1994) Las empresas brasileñas: internacionalización y ajuste a la globalización de los mercados. Cepal, 1994.

DUNNING, J. H. (1980) "Toward an eclectic theory of international production: some empirical tests”. Journal of International Business Studies, 11 (1), 1980.

DUNNING, J.H., R. HOESEL, e R. NARULA (1997) Third World multinationals revisited: new developments and theoretical implications. University of Reading, 1997 (Discussion Papers in International Investment and Management, 227)

ESPANHA - Ministerio de Industria, Turismo y Comercio (2003) . http://www.mcx.es/polco/InversionesExteriores/estadisticas/cuadros/FlujosExtranjerasSemestrales.htm

ESTADOS UNIDOS — BEA, Bureau of Economic Analysis (2003) - www.bea.gov

FERRAZ, J.C, L. HAGUENAUER e D. KUPFER (1996) “Competição e Internacionalização na Indústria Brasileira”. In: BAUMANN, R. (org) O Brasil e a Economia Global. Editora Campus, 1996.

FERRAZ, J.C., D.S. KUPFER e L. HAGUENAUER (1996) Made in Brazil: desafios competitivos para a indústria. Rio de Janeiro: Campus. 
GOULART, L., H.V. BRASIL, e C.A. ARRUDA (2000) "A evolução na dinâmica de internacionalização". Revista Brasileira de Comércio Exterior, Rio de Janeiro.

LOPEZ, A. (1999) "El caso brasileño". In: CHUDNOVSKY, D., KOSAKOFF, B. \& LOPEZ, A. (eds) Las multinacionales latinoamericanas: sus estrategias en un mundo globalizado. Buenos Aires: Fondo de Cultura Econômica.

PORTUGAL — Agência Portuguesa para o Investimento (2004) — www.api.pt

PORTUGAL — Banco de Portugal, (2001) - www.bportugal.pt

PORTUGAL — INE — Instituto Nacional de Estatística (2000) — www.ine.pt

UNCTAD, World Investment Report, (2002).

UNCTAD, World Investment Report, (2004).

VEIGA, P. M. e R. IGLESIAS (2002). "Promoção de Exportações via Internacionalização das Firmas de Capital Brasileiro”. In: PINHEIRO, A. C., MARKWALD, R. \& PEREIRA, L. V. (orgs) O Desafio das Exportações. Rio de Janeiro: BNDES. 